\title{
The Effect of Nigella Sativa on Clinical Improvement of Laryngopharyngeal Reflux Patients
}

\author{
Lusia $^{1 *}$, Farokah ${ }^{2}$, Rery Budiarti ${ }^{2}$ \\ ${ }^{1}$ Medical Faculty, Diponegoro University, Indonesia
}

${ }^{2}$ Teaching Staff, OtoRhinoLaryngology Head and Neck Department, Diponegoro University, Indonesia

\begin{abstract}
Keywords:
Laryngopharyngeal

Reflux,

Nigella sativa

Omeprazol,

Reflux Symptoms Index,

Reflux Finding Score,
\end{abstract}

*) Correspondence to: kaitoechizen@gmail.com

Article history:

Received 21-09-2020

Accepted 03 - $12-2020$

Availableonline10-12-2020

\begin{abstract}
Background: Laryngopharyngeal Reflux (LPR) describes as retrograde reflux from gaster into the laryngopharynx because of the premature relaxation upper esophageal sphincter. The management of LPR patients includes lifestyle and dietary arrangements, medical therapy and surgical management. Nigella sativa (NS) / black cumin has anti-inflammatory, anti-oxidant and gastroprotective effects that are expected to provide clinical improvement in LPR patients.

Objective: The purpose of this study was to determine the effectiveness of NS on the clinical improvement of LPR patients

Methods: This research is an intervention study using pre and post-test design methods of 34 LPR patients in Dr. Kariadi, hospital and 2 affiliated hospitals from November 2019 - March 2020.

Results: 24 patients with complete data while 10 patients were unable to evaluate RFS because of a pandemic. The treatment group (15 patients) were given omeprazole $20 \mathrm{mg} / 12$ hours plus NS $1000 \mathrm{mg} / 12$ hours orally and control group (9 patients) were given omeprazole $20 \mathrm{mg} / 12$ hours orally and placebo. Data were tested by Shapiro Wilk test, followed by the appropriate parametric test, and Fisher's exact test. There were no differences in clinical improvement in LPR based on RSI and RFS values between groups given additional NS and groups without NS, p 0.105. Conclusion: there were no significant differences in clinical improvement between groups given additional NS and groups without NS.
\end{abstract}

DIMJ, 2020, 1(1), 34-38 DOI: https:// doi.org/10.14710/dimj.v1i2.8992

\section{Introduction}

Laryngopharyngeal Reflux (LPR) decribes as retrograde reflux from gaster into the laryngopharynx because of the premature relaxation upper esophageal sphincter. The premature relaxation of upper esophageal sphincter causes refluxate to rise into the laryngopharyngeal area. ${ }^{1}$ The result is a pathological process that is chronic inflammation in the laryngopharyngeal area. Patients who come to the ENT clinic, about 4$10 \%$ have LPR complaints. ${ }^{2}$ Nine questions in the Reflux Symptoms Index (RSI) are used to measure complaints experienced by patients. Reflux Finding Score (RFS) which consist of eight items found from the laryngopharyngeal clinical examinations that associated with LPR patient complaints. LPR is diagnosed by RSI > 13 and RFS $>7 .{ }^{1}$

Nigella sativa (black cumin) is a species of the genus Nigella which has 25 species of plants that belong to the Ranunculaceae family. The liquid extract of Nigella sativa has been researched to have immunomodulatory effect, anti-inflammatory, analgesic, antipyretic, anti-secretory gastric activity, anti-ulcer activity in the gastrointestinal tract, hepatoprotective, antimicrobial, and anticancer. . $^{-}$

The administration of 2 grams Nigella sativa a day can have an eradicating effect on Helicobacter pylori. ${ }^{4}$ SSeveral studies mention Nigella sativa in liquid form provides a protective effect on the gastric mucosa. The effectiveness of Nigella sativa in the gastrointestinal tract shows that Nigella sativa increases mucin, reduces acidity and glutathione levels and decreases histamine release in the gastric. .5 
Gastroprotective effects of Nigella sativa occur due to proton pump inhibition, gastric acid secretion and neutrophil infiltration as well as increased mucin secretion. ${ }^{-3}$ Nigella sativa also has effectiveness as an anti-inflammatory and anti-oxidant by inhibiting proinflammatory mediators. $\underline{6}$ The effect of Nigella sativa as anti-inflammatory, anti-oxidant and gastroprotective is what is expected to provide clinical improvement in LPR patients. ${ }^{3}, \underline{6}$ Research on the effectiveness of Nigella sativa in LPR patients has never been done.

\section{Methods}

The study involved 34 patients, divided into 17 patients as a control group and 17 patients as a treatment group. Qualified samples are LPR patients with RSI scores $>13$ and RFS score $>7$ at Merpati ENT-HNS clinic and Central Surgery Installation of Dr. RSUP. Kariadi Semarang, ENT-HNS clinic Dr. Soetrasno Rembang Hospital and Dr. Soeselo Slawi in November 2019 - March 2020. The treatment group was LPR patients who received standard LPR therapy (Omeprazole $20 \mathrm{mg}$ every 12 hours) added with 1 gram liquid Nigella sativa wrapped in capsules, gived every 12 hours. The control group was LPR patients who received standard therapy and placebo. The laryngopharyngeal examination were carried out with the Olympus BFP 160 flexible laryngoscopy and the scope of Olympus Exera 2 and Ambu Scope. 8 patients in the control group and 2 patients in the treatment group were unable to do an RFS examination at the end of the study because of a pandemic. This study used a Randomized Controlled Trial test with a Pre Test and Post Test Control Trial Group design. Statistical data analysis uses the SPSS (Statistical Product and Service Solution) program. Data were tested by Shapiro Wilk test, followed by the appropriate parametric test, Fisher's exact test.

Ethical clearance from the Medical Research Ethics Commission FK UNDIP / RSUP Dr. Kariadi Semarang on 5 November 2019 with number 395 / EC / KEPK-RSDK / 2019. Permission from RSUP Dr. Kariadi on 28 November 2019 number DP0.2.01 / I.II / 6539/2019. A permit to carry out research from the RSUD Dr. Soetrasno Rembang on February 9, 2020. Director's license Dr. Soesilo Slawi with number 005/27/3994/2020 on 7 February 2020 based on recommendations from the Research Ethics Committee of RSUD Dr. Soeselo Slawi on 5 February 2020.

\section{Results}

Table 1 explains the the characteristics Dof the subjects including age, sex, BMI, and diet during the study

Table 1. The characteristic of the subjects

\begin{tabular}{|c|c|c|c|c|c|}
\hline \multirow{3}{*}{ Variabels } & \multicolumn{4}{|c|}{ Group } & \multirow{3}{*}{$p^{¥}$} \\
\hline & \multicolumn{2}{|c|}{ Treatment $(n=15)$} & \multicolumn{2}{|c|}{ Control $(n=9)$} & \\
\hline & $\mathbf{n}$ & $\%$ & $\mathbf{N}$ & $\%$ & \\
\hline \multicolumn{6}{|l|}{ Age } \\
\hline $18-40$ years & 5 & 33,3 & 2 & 22,2 & \multirow[t]{2}{*}{0,669} \\
\hline $41-60$ years & 10 & 66,7 & 7 & 77,8 & \\
\hline \multicolumn{6}{|l|}{ Sex } \\
\hline Male & 1 & 6,7 & 2 & 22,2 & \multirow[t]{2}{*}{0,533} \\
\hline Female & 14 & 93,3 & 7 & 77,8 & \\
\hline \multicolumn{6}{|l|}{ BMI } \\
\hline Underweight & 0 & 0 & 1 & 11,1 & \multirow[t]{4}{*}{0,274} \\
\hline Normal & 9 & 60 & 5 & 55,6 & \\
\hline Overweight & 3 & 20 & 3 & 33,3 & \\
\hline Obesity & 3 & 20 & 0 & 0 & \\
\hline \multicolumn{6}{|l|}{ Diet } \\
\hline Coffee & 3 & 20 & 2 & 22,2 & 1,000 \\
\hline Tea & 13 & 86,7 & 8 & 88,9 & 1,000 \\
\hline Spicy foods & 10 & 66,7 & 5 & 55,6 & 0,678 \\
\hline
\end{tabular}

Most subjects with age ranges 41-60 years in both groups. More female sex in the treatment group (14 patients) and control (7 patients). Both research groups had normal BMI. Tea is a type of beverage that is often consumed by subjects followed by spicy foods in both groups. None of the subjects consumed soft drinks, alcohol and smoking in both groups. There were no significant differences in age, sex, BMI and diet in the two groups. 


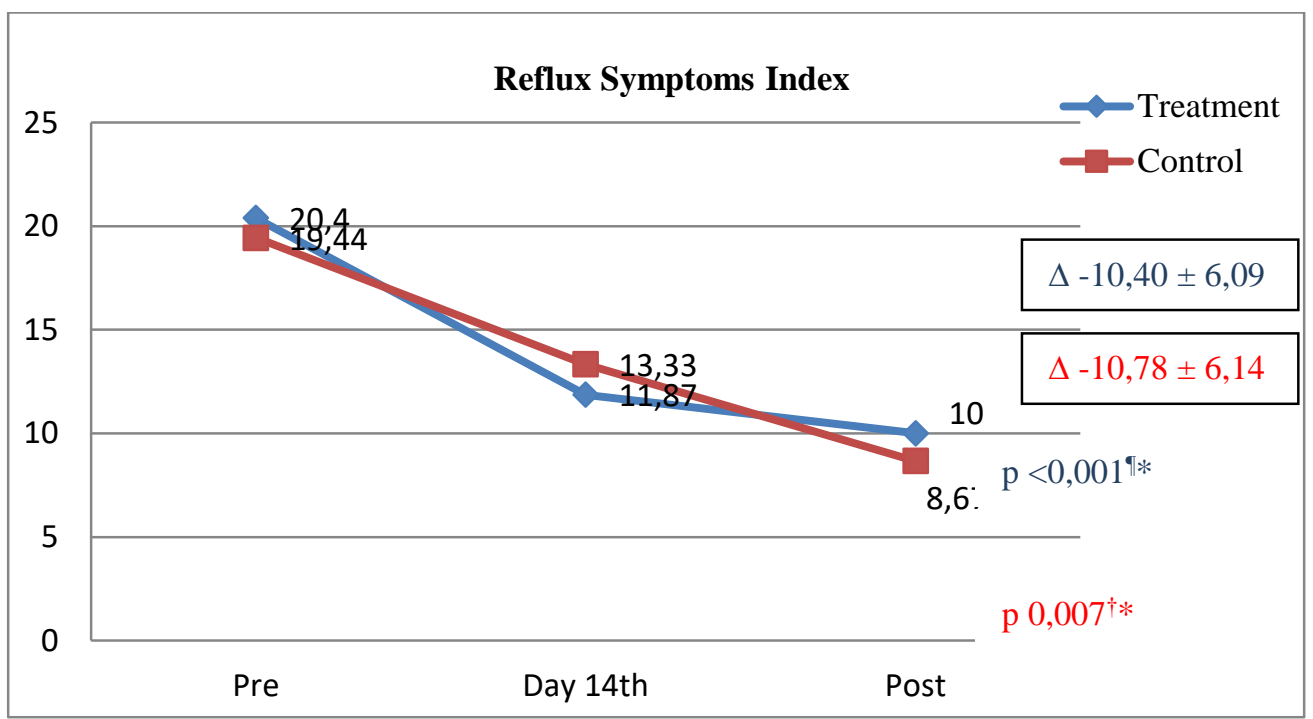

Figure 1. Mean of RSI in the control and treatment groups

Figure 1 shows the RSI in the control and treatment groups before, day 14th evaluation and after the study. There were significant differences in the RSI in each control group and treatment before and after the study with $p<0.05$. The decrease in RSI was seen in the control and treatment groups from before to after the study, which means that there was an improvement in complaints experienced by the subjects.

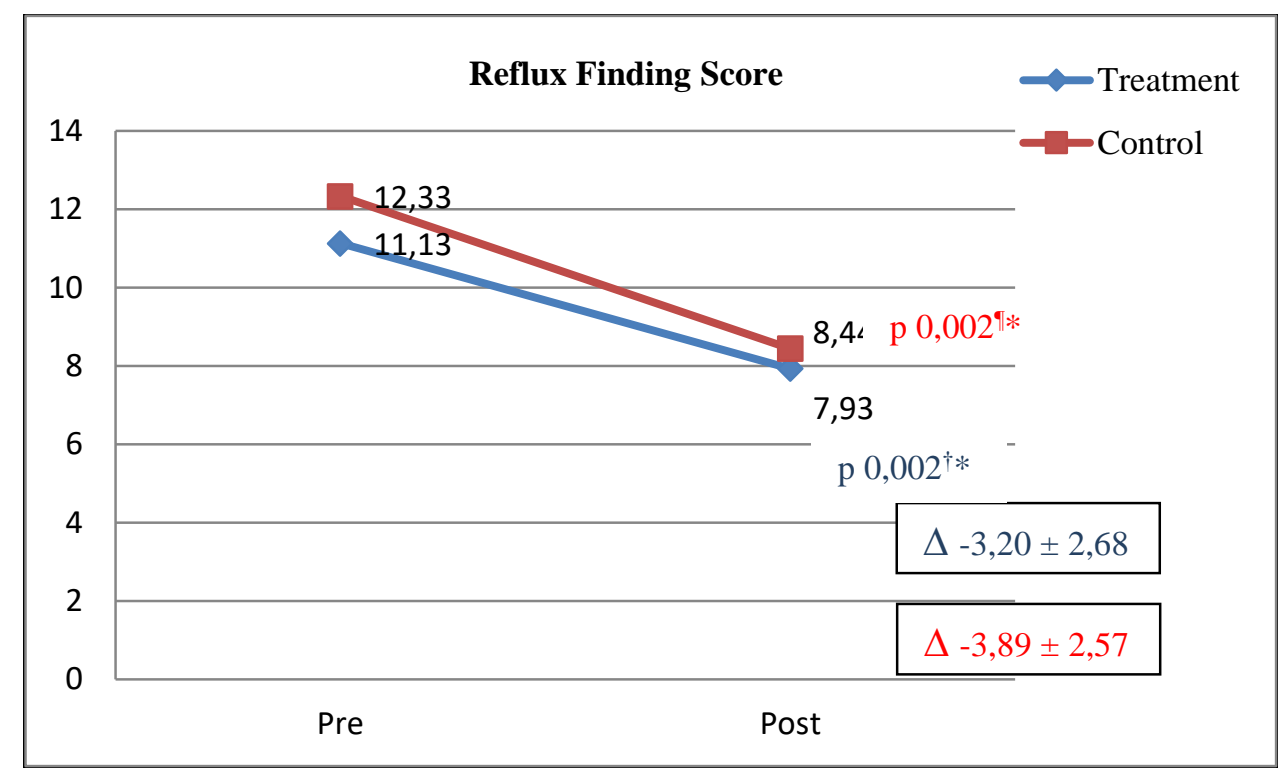

Figure 2. Mean of RFS in control and treatment groups

Figure 2 shows the significant differences in RFS in each control group and the treatment before and after treatment with $p<0.05$. The decrease in RFS in the control and treatment groups from before the study to after the completion of the study meant that there was an improvement when evaluating with flexible laryngoscopy.
Tabel 2. Difference RSI and RFS between control and treatment groups

\begin{tabular}{|c|c|c|c|}
\hline \multirow{2}{*}{ Variabels } & \multicolumn{2}{|c|}{ Groups } & \multirow[b]{2}{*}{$\mathbf{p}$} \\
\hline & Treatment & Control & \\
\hline Delta RSI & $\begin{array}{c}-10,40 \pm \\
6,09\end{array}$ & $\begin{array}{c}-10,78 \pm \\
6,14\end{array}$ & 0,952 \\
\hline $\begin{array}{l}\text { Delta } \\
\text { RFS }\end{array}$ & $-3,20 \pm 2,68$ & $-3,89 \pm 2,57$ & $0,542^{\S}$ \\
\hline
\end{tabular}


Table 2 shows no significant differences in the decrease in RSI and RFS between groups with p> 0.05 . But there was clinical improvement in both groups (decrease in RSI> 3 and RFS> 2).

Tabel 3. Clinical Improvement in RSI and RFS between groups

\begin{tabular}{|c|c|c|c|}
\hline \multirow{2}{*}{ Improvement } & \multicolumn{2}{|c|}{ Groups } & \multirow[b]{2}{*}{$\mathbf{p}$} \\
\hline & Treatment & Control & \\
\hline Yes & $6(40 \%)$ & $7(77,8 \%)$ & $0,105^{£}$ \\
\hline No & $9(60 \%)$ & $2(22,2 \%)$ & \\
\hline
\end{tabular}

Table 3 shows the clinical improvement assessed based on a decrease in the two values, the RSI and RFS values between groups which were not significantly different.

\section{Discussion}

The study included 24 LPR patients with the lowest age of 19 years and the highest of 60 years. Most age groups are 41 - 60 years. These results are the same as the results of a study conducted by Lechien et al in LPR patients in 3 hospitals in Germany with the most age group 41-60 years. $\frac{7}{}$ Research conducted on 229 patients given PPI, found that increasing age can cause accumulation of stomach acid but it can also occur damage from intrinsic defense, gastric emptying mechanism for longer, changes in resistance of the mucosa. This is why the RSI is greater in patients with older. ${ }^{-}$The results showed more LPR patients in the female sex (21 patients) compared to men (3 patients). Recent research suggests that women have low levels of Carbonic Anhydrase isoenzyme III (CA-III) so that LPR complaints in women appear first when compared to men. CA-III is an important defense mechanism by increasing the buffering capacity of inflammation. ${ }^{9}$ The highest BMI in the study subjects was in the normal BMI category (9 subjects in the treatment group and 5 subjects in the control group). The relationship between LPR and obesity cannot be explained with certainty. Eating arrangements, weight loss (BMI <25 kg / m2) will reduce intraabdominal pressure, gastric distension, and relaxation of the lower esophageal sphincter thereby reducing reflux. ${ }^{1}$ The study by Lechien involving 65 LPR patients in Belgium showed significant improvements in the group that maintained their diet and lifestyle modification by not consuming foods such as soft drinks, caffeine, alcohol, fatty foods and smoking..

This study showed a decrease in the mean RSI before, day 14 and after the study in both groups
(Figure 1). The mean of RSI had decrease significantly at the end of the study when compared with the mean of RSI before the study. It means an improvement in complaints from research subjects. This can occur because each group received standard therapy and then added placebo in the control group and Nigella sativa in the treatment group. Nigella sativa has never been studied in patients with LPR before. Research conducted on 88 dyspepsia patients showed improvement in reflux complaints, reduction in the number of Helicobacter pylori after being given Nigella. ${ }^{4}$ Animal studies given Nigella sativa showed decreased gastric acid volume, pepsin concentration, gastric acidity..$^{10}$ This study shows that the mean RFS before and after the study in the control group was higher when compared to the treatment group (Figure 2 ). The mean of RFS also had decrease significantly at the end of the study. Research on the effects of Nigella sativa on the laryngeal mucosa has never been done before. Research conducted shows the proton pump inhibition process, decreased gastric secretion, increased gastric $\mathrm{pH}$, improved gastric mucosa and increased mucus secretion that protects the epithelial layer so that it is expected to improve the laryngeal mucosal picture on endoscopic examination and reduce complaints in LPR patients. $11, \underline{12}$ The effect of omeprazole as a standard therapy that works to reduce the activation of gastric acid secretion, maintain intragastric $\mathrm{pH}>4$ so that there is an improvement during endoscopic examination. $1, \underline{13}$, 14 Difference between RSI and RFS between groups was no significant. But there was a clinical improvement in both groups marked by a decrease in RSI $>3$ and RFS $>2$, although it was not statistically significant (Table 3 ).

\section{Conclusion}

There were no significant differences in clinical improvement between groups given additional NS and groups without NS.

\section{Reference}

1. Blumin JH. Laryngopharyngeal Reflux. In: Johnson JT RC, editor. Bailey's Head and Neck Surgery Otolaryngology. 1. 5th ed ed. Baltimore: Lippincott Williams \& Wilkins; 2015. p. 958-77.

2. Axford SE, Sharp N, Ross PE, Pearson JP, Dettmar PW, Panetti M, et al. Cell Biology of laryngeal epithelial defenses in health and disease : preliminary studies Ann Otol Rhinol Laryngol. 2001;110:1099-108. 
3. Shakeri F, Gholamnezhad Z, Mégarbane B, Rezaee R, Boskabady MH. Gastrointestinal effects of Nigella sativa and its main constituent, thymoquinone: a review. Avicenna Journal Phytomed. 2016;6(1):9-21.

4. Salem EM, Yar T, Bamosa AO, Al-Quorain A, Yasawy MI, Alsulaiman RM, et al. Comparative study of Nigella Sativa and triple therapy in eradication of Helicobacter Pylori in patients with non-ulcer dyspepsia. Saudi J Gastroenterol. 2010 Jul-Sep;16(3):207-14. PubMed PMID: 20616418. Pubmed Central PMCID: 3003218.

5. Lechien JR, Huet K, Khalife M, De Marrez LG, Finck C, Harmegnies B, et al. Alkaline, protein, low-fat and low-acid diet in laryngopharyngeal reflux disease: Our experience on 65 patients. Clin Otolaryngol. 2019 May;44(3):379-84. PubMed PMID: 30548197. Epub 2018/12/15. eng.

6. Kazemi M. Phytochemical Composition, Antioxidant, Anti-inflammatory and Antimicrobial Activity of Nigella sativa L. Essential Oil. Journal of Essential Oil Bearing Plants. 2014;17(5):1002-11.

7. Lechien JR, Finck C, Khalife M, Huet K, Delvaux V, Picalugga M, et al. Change of signs, symptoms and voice quality evaluations throughout a 3- to 6-month empirical treatment for laryngopharyngeal reflux disease. Clinical otolaryngology : official journal of ENT-UK ; official journal of Netherlands Society for OtoRhino-Laryngology \& Cervico-Facial Surgery. 2018;43(5):1273-82. PubMed PMID: 29768736.

8. Lee YC, Lee JS, Kim SW, Kwon KH, Eun YG. Influence of age on treatment with proton pump inhibitors in patients with laryngopharyngeal reflux disease: a prospective multicenter study. JAMA Otolaryngol Head Neck Surg. 2013 Dec;139(12):1291-5. PubMed PMID: 24201320.

9. Gao CK, Li YF, Wang L, Han XY, Wu T, Zeng FF, et al. Different cutoffs of the reflux finding score for diagnosing laryngopharyngeal reflux disease should be used for different genders. Acta oto-laryngologica. 2018;138(9):848-54. PubMed PMID: 29852801.

10. Saleh MIA, Isa AI, Imam A, Mabrouk MA, Musa KY, Mohammed A, et al. Antisecretory and antiulcerative effects of ethyl acetate fraction of Nigella sativa (L.) Seed extract in rats. Bayero Journal of Pure and Applied Sciences. 2016;8(2):202.

11. El-Abhar HS, Abdallah DM, Saleh S. Gastroprotective activity of Nigella sativa oil and its constituent, thymoquinone, against gastric mucosal injury induced by ischaemia/reperfusion in rats. $\mathbf{J}$ Ethnopharmacol. 2003 Feb;84(2-3):251-8. PubMed PMID: 12648823. Epub 2003/03/22. eng.

12. Obeid AE, Eldin K, Tahir HE, Elhag H, Haseeb AM. Anti Ulcerogenic Effect of Nigella Sativa L. Melanin. World Journal of Pharmaceutical Research. 2016;5(1):1579-93.

13. Strand DS, Kim D, Peura DA. 25 Years of Proton Pump Inhibitors: A Comprehensive Review. Gut and Liver. 2017;11:27-37.

14. Lechien JR, Schindler A, Marrez LGD, Hamdan AL, Karkos PD, Harmegnies B, et al. Instruments Evaluating the Clinical Findings of Laryngopharyngeal Reflux: A Systematic Review. The Laryngoscope. 2018;00:1-17. 